\title{
Editorial
}

\section{Assessing Psychotherapy Competence: A Beginning}

\author{
Joel Yager, M.D. \\ Jerald Kay, M.D. \\ Lisa Mellman, M.D.
}

$\mathrm{T}_{\mathrm{c}}^{\mathrm{k}}$ he recent requirement by the Accreditation Council on Graduate Medical Education's Residency Review Committee (RRC) for Psychiatry that programs "must demonstrate that residents have achieved competency" in at least five forms of psychotherapy, including brief therapy, cognitive-behavioral therapy, combined psychotherapy and psychopharmacology, psychodynamic therapy, and supportive therapy, certainly got the field's attention. The requirements come as the result of several historical trends, including rising interest in medicine to increase public accountability through demonstrations of practitioner competence $(1,2)$, ongoing efforts over past decades to improve the quality of psychiatric training, as exemplified by several national conferences and activities of the American Association of Directors of Residency Training (AADPRT) $(3,4)$, and specific interests within the American Psychiatric Association (APA) and other organizations to ensure that psychotherapy training remains a high priority for the profession $(5,6)$. Just when forces such as managed care and the strong ascendance of biological psychiatry threatened to decrease the relevance of psychotherapy for psychiatric practice, the juggernaut defining specialty-specific competencies in graduate medical education presented those in organized psychiatry who value psychotherapy a unique opportunity to require strengthening of psychotherapy training in residency programs. Along with mandates for the six general competencies required of all medical specialties, the only new specific competencies enacted by psychiatry's RRC focus on psychotherapies.

These developments carry a range of implications. The good news is that increased attention and resources will have to be devoted to psychotherapy training, shifting from very nonspecific expectations in order to concentrate on specific goals, quality and quantity of teaching, skill acquisition and accountability. The well-intended result should be to strengthen psychotherapy training in all programs, some of which have, historically, offered little psychotherapy training of any sort. Difficulties that must be reckoned with include already overloaded training directors and departments now having to contend with several intended and unintended challenging consequences stemming from these requirements. First, mandating competencies means that resources will have to be devoted not only to providing all the specific types of psychotherapy training (not readily available in many departments) but also to assessing residents' competencies. The bureaucratic headaches may be considerable. Second, it becomes quickly obvious that definitions of competence are not self-evident, and agreements as to how such competencies can be meaningfully assessed are not universally shared. One important cautionary comment concerning competence assessment was recently offered by Michael Whitcomb, the editor of Academic Medicine (7), who suggests that graduate medical education programs should not be required to develop and im-

Dr. Yager is Professor and Vice Chairman for Education and Academic Affairs at the University of New Mexico School of Medicine, Albuquerque, New Mexico and Professor Emeritus, Department of Psychiatry and Biobehavioral Sciences, University of California, Los Angeles School of Medicine, Los Angeles, CA. Dr. Yager is also with the Board of Trustees for the American Psychiatric Institute for Research and Education (APIRE). Dr. Kay is Professor and Chairman of the Department of Psychiatry at Wright State University School of Medicine, Dayton, Ohio. Dr. Mellman is Associate Clinical Professor and Associate Director of Training in the Department of Psychiatry, Columbia University College of Physicians and Surgeons, New York State Psychiatric Institute, New York, NY. Address correspondence to Dr. Yager, Department of Psychiatry, University of New Mexico School of Medicine, 2400 Tucker NE, Albuquerque, NM 871315326, jyager@unm.edu (E-mail).

Copyright (c) 2003 Academic Psychiatry. 
plement new methods for documenting the performances of residents that will likely lead to the testing of residents in "structured and largely artificial settings." Instead, he advocates that programs should be required to formalize what is now largely informal: observations that faculty make on a daily basis concerning the ways in which residents perform when providing care to the patients assigned to them. Implicit obstacles in this commonsense approach loom larger for competence assessment in psychotherapy than for other procedures of medicine. Definitional problems rush to the forefront. In contrast to the summative competency definitions for procedural competencies used in other parts of medicine ("he can certainly do a great job of removing an appendix from start to finish"), psychotherapy competencies are not so cut-and-dried, nor are they so readily observed. For the moment, we will need to content ourselves with a series of formative assessments, in which residents demonstrate some competencies of knowledge and skill, perhaps showing that they are "good enough" psychotherapists, not necessarily master psychotherapists, by the time they graduate. But, do we agree on what constitutes "good enough"? Embedded in these issues is a myriad of future political, research, and training agendas. For example, powerful forces are already advocating that the RRC mandate that training be limited to "evidence-based" therapies, including psychotherapies. The field struggles with building and operationalizing consensus definitions of competencies and has to develop valid, feasible (undoubtedly less than idealistic) ways for ensuring and assessing these competencies in all training programs-not only the largest and best resourced ones-without bankrupting departments.

Facing this turning point in psychiatry's educational history, we have attempted to compile a stateof-the- art collection to inform psychiatric educators about how these developments evolved, what is currently being done with respect to psychotherapy assessment practice and research, and what may happen in the future. Authors contributing to this issue have been wrestling with ways to assess particular psychotherapies for their home departments and the field. Readers will find ideas ranging from simple, practical applications for small programs to more elaborate efforts.

Miller et al. describe the historical and zeitgeist background in which subjects of psychotherapy competencies for psychiatry evolved. Mellman and Beresin review the significant efforts managed by the AADPRT to provide guidance for the field. We then present discussions of the efforts made by specific programs to deal with local endeavors for assessing psychotherapy competence. We begin with a description of comprehensive, large-scale programs at McMasters University presented by Weerasekera et al. Additionally, we offer a description of the background work and applications at the University of Missouri as reported by Manring et al., and the Briones and Giordano description of practical methods for psychotherapy competence assessment that they are developing for a resource-poor program at Texas Tech University in El Paso.

Two of the following papers describe developments focusing on specific psychotherapies. Sudak et al. review the considerable progress made for cognitive-behavior therapy (assessment methods far ahead of the rest of the psychotherapy field) and Summers and Barber focus on the assessment of basic therapeutic alliance. Bienenfeld et al. describe a program at Wright State University for assessing how the skills and knowledge of residents are relevant to graduates, an approach that will be necessary for psychotherapy training in order to demonstrate the ultimate utility of our training. Finally, Yager and Bienenfeld grapple with a fundamental question regarding the assessment of psychotherapy competencies (i.e., How competent are the assessors to conduct the assessments they're supposed to be conducting?). They attempt to offer what may be practical perspectives.

We trust that these discussions will stimulate readers' thinking, provide guidance, and inform local responses to these challenges, and we anticipate that these reports represent only the beginning of ongoing efforts. Many innovative solutions can be expected in the future from the fertile minds inhabiting our profession. 


\section{References}

1. Jones DJ: Accountability for professional education and certification-another idea whose time has come. Am J Med Qual 1998; 13:1-2.

2. Murray E, Gruppen L, Catton P, Hays R, Woolliscroft JO: The accountability of clinical education: its definition and assessment. Med Educ 2000; 34: 871-9

3. Yager J, Elliott RL, Smith N, Strauss GD, Templeton B, Thompson JW: The quality of psychiatric residency programs: the assessment of programs and options for distributing psychiatric residents in the service of health care reform. 1999; Academic Psychiatry 23:61-70
4. Yudkowsky R, Elliot R, Schwartz A: Two perspectives on the indicators of quality in psychiatry residencies: program directors' and residents'. Acad Med 2002; 77:57-64

5. Clemens NA, Bebchuk W, Beitman BD et al: Disputing psychiatry's redefinition. Am J Psychiatry. 1997; 154:1633-5

6. Gabbard GO, Kay J: The fate of integrated treatment: whatever happened to the biopsychosocial psychiatrist? Am J Psychiatry 2001; 158:1956-1963

7. Whitcomb, ME: Competency-based graduate medical education? of course! but how should competency be assessed? Acad Med 2002; 77: 359-360 